UCRL-JC- -106010

DE92 001896

OCT 251991

\title{
Remote Measurements of Actinide Species in Aquesous Solutions Using an Optical Fiber Photoacoustic Spectrometer
}

\author{
R.E. Russo \\ P.B. Robouch \\ R.J. Silva \\ This paper was prepared for the \\ MRS International Symposium on the Scientific Basis \\ for Nuclear Waste Management XIV \\ Symposium $P$ \\ Boston, MA \\ November 26-29, 1990
}

September 26, 1990

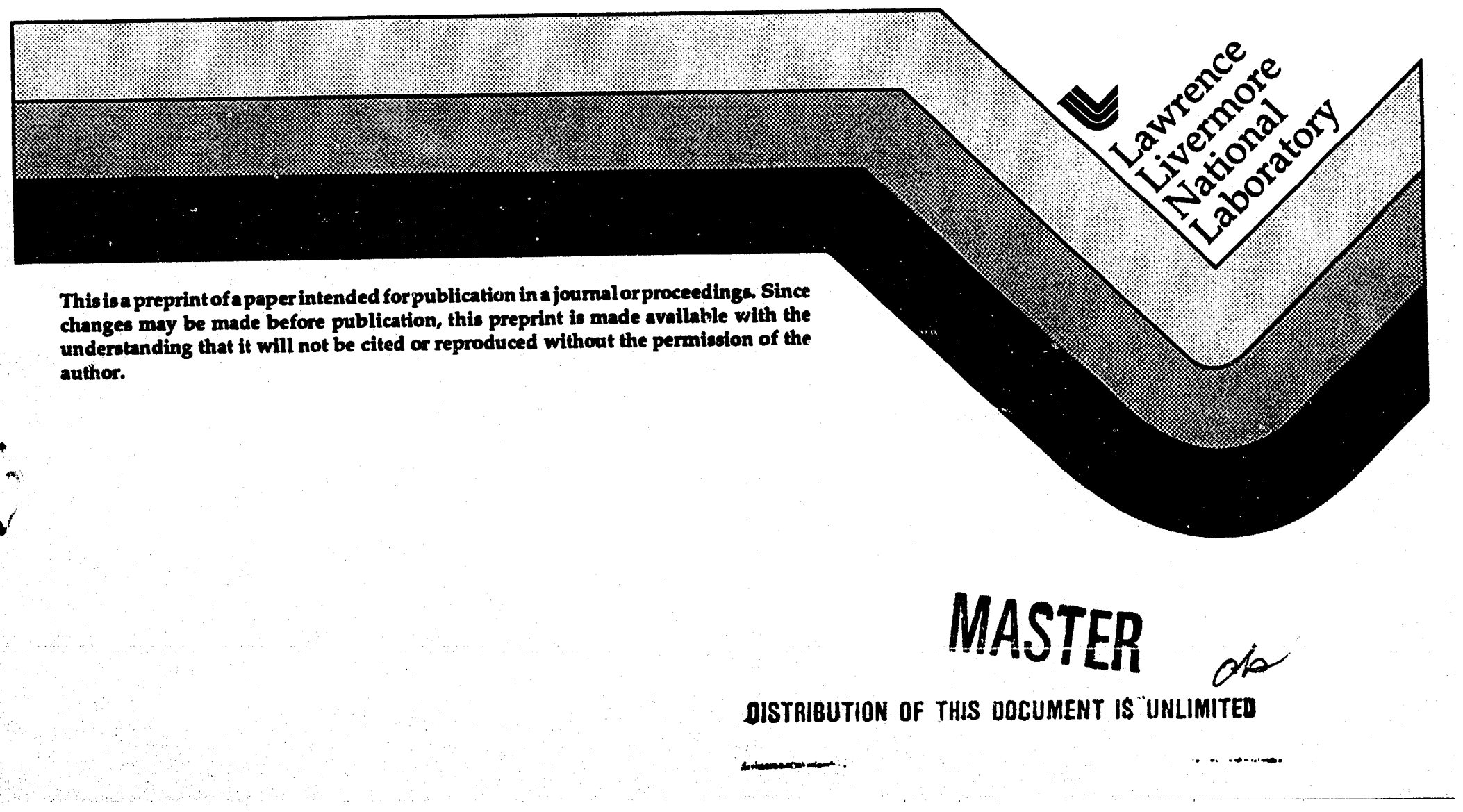


This document was prepared as an account of work sponsored by an agency of the United States Government. Neither the United States Government nor the University of California nor any of their employees, makes any warranty, express or implied, or assumes any legal liability or responsibility for the accuracy, completeness, or usefulness of any information, apparatus, product, or process disclosed, or represents that its use would not infringe privately owned rights. Reference herein to any specific cotamercial products, process, or service by trade name, trademark, manufacturer, or otherwise, does not necessarily constitute or imply its endorsement, recommendation. or favoring by the United States Government or the University of California. The views and opinions of authors expreased herein do not necessarily state or reflect those of the United States Government or the University of California, and shall not be used for advertising or product endersement purposes. 
REMOTE MEASUREMENTS OF ACTINIDE SPECIES IN AQUEOUS SOLUTIONS USING AN OPTICAL FIBER PHOTOACOUSTIC SPECTROMETER

\author{
RICHARD E. RUSSO", PIOTR B. ROBOUCH“" and ROBERT J. SILVA“" \\ "Lawrence Berkeley Laboratory, Applied Science Division, MS 90-2024, \\ Berkeley, CA 94720 \\ "Lawrence Livermore National Laboratory, Nuclear Chemistry Division, L-396, \\ Livermore, CA 94550
}

\title{
ABSTRACT
}

A photoacoustic spectrometer, equipped with an 85 meter optical fiber, was used to perform absorption measurements of lanthanide and actinide samples, located in a glovebox. The spectrometer was tested using aqueous solutions of praseodymium and americium ions; the sensitivity for remote measurements was found to be similar to that achieved in the laboratory without the fiber.

\section{INTRODUCTION}

Photoacoustic spectroscopy (PAS) is an optical absorption technique for chemical analysis [1-4], allowing for sensitivities on the order of $10^{-6} \mathrm{~cm}^{-1}$. PAS has been demonstrated as an excellent technique for the detection and identification of rare earth and actinide species [5-9]. It is a non-contact and non-destructive method capable of determining oxidation states and studying complexation at high sensitivity levels; it's sensitivity surpasses that of conventional absorption spectroscopy by several orders of magnitude. The measurement of actinide species at sub-micromolar concentrations in aqueous solutions has become increasingly important for the determination of thermodynamic properties, for research in high-level nuclear waste management, and for environmental monitoring and characterization. We developed a photoacoustic spectrometer for remote measurements of rare earth and actinide species using an optical fiber to transmit the excitation laser light to a sample solution in a glovebox located in a separate laboratory, 85 meters from the laser and detection electronics. The system is ideally suited for conducting actinide research on highly radioactive species in a protected enclosure without requiring sampling and the risk of contaminating the laser laboratory.

\section{EXPERIMENTAL}

The experimental diagram for the optical fiber photoacousti spectrometer is shown in Figure I. A pulsed Nd:YAG pumped dye laser (Quanta Ray; DCR 3G/PDL) was used as the excitation light source. Coumarin LD-466 and C-500 (Exciton) were chosen to overlap the absorption bands of praseodymium (at 468 and $482 \mathrm{~nm}$ ) and 
americium (at $503 \mathrm{~nm}$ ). A $35 \mathrm{~mm}$ lens was employed to focus the dye-laser light into the 85 meter multimode optical fiber (core diameter: $600 \mu \mathrm{m}$; cladding diameter: $750 \mu \mathrm{m}$; Fiberguide: SPC-600Z). At the remote location, a $10 \mathrm{X}$ microscope objective was used to collimate the light from the fiber and direct it into a cuvette containing the sample solution. The lens produced a collimated beam approximately $6 \mathrm{~mm}$ in diameter.

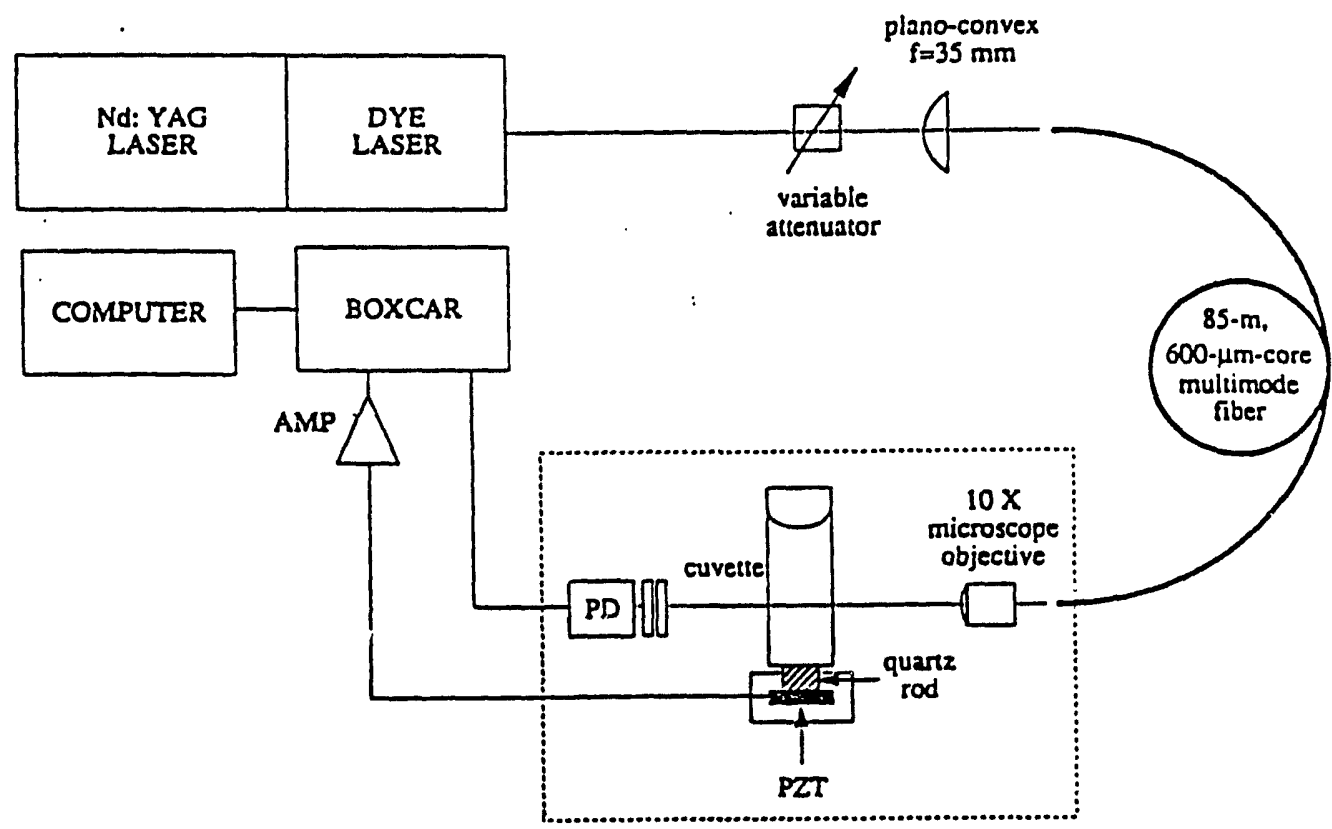

Figure I. Experimental diagram for the optical fiber photoacoustic spectrometer. Dashed box encloses components at the remote location.

The photoacoustic cell-assembly consisted of a quartz cuvette (Suprasil) acoustically coupled to a cylindrical quartz rod and a piezoelectric transducer (PZT5A). The signal from the PZT was amplified by a charge sensitive preamplifier (Ortec; 142C) and conditioned by a spectroscopy amplifier (Ortec; 570). Gated detection was employed using a boxcar integrator (Stanford Research Systems; SR250). A filter/photodiode assembly was used as a light trap to collect the beam exiting the cuvette. The photodiode (United Detector Technology; 10DFP) monitored the laser energy in order to correct for pulse to pulse energy fluctuations and to ratio the measured photoacoustic spectra to the dye gain power profile. The signal from the photodiode was recorded using a second boxcar gate. Photoacoustic spectra were recorded by scanning the dye laser wavelength and measuring the change in amplitude of the acoustic signal on the boxcars using a personal computer.

All the components for the remote part of the photoacoustic spectrometer (microscope objective, cell assembly, photodiode) were mounted on a one-inch thick aluminum plate. The simple light-weight portable unit measured 16 " $\times 8$ " and could be easily positioned within the glovebox. 


\section{RESULTS}

The transmission through the entire optical system was measured to be approximately $53 \%$ at $470 \mathrm{~nm}$. This value is a result of Fresnel losses in the optical components and the transmission efficiency of the fiber at this wavelength. The maximum photoacoustic sensitivity was found when the center of the beam was approximately $29 \mathrm{~mm}$ above the surface of the PZT.

At first, praseodymium-ion aqueous solutions were used to optimize the photoacoustic experimental configuration by maximizing the photoacoustic signal amplitude and by reducing electrical noise. The coordination chemistry of $\mathrm{Pr}^{3+}$ is similar to that of trivalent actinide ions in solution. Therefore, the system could be developed and tested using non-radioactive solutions. Using $1 \mathrm{~mJ} /$ pulse at the cuvette, photoacoustic spectra were measured for $\mathrm{Pr}^{3+}$ solutions in the concentration range from $10^{-4}$ to $8^{*} 10^{-6} \mathrm{M}$ in $0.01 \mathrm{M} \mathrm{HClO}_{4}$ (Figure $\Pi$ a). The "proof-of-principle" achieved, the same experiment was performed using americium solutions $\left(3^{*} 10^{-8} \leq[\mathrm{Am}] \leq 10^{-6} \mathrm{M}\right)$ in $0.01 \mathrm{M} \mathrm{HClO}_{4}$ (Figure Ib).

The absorptivity of water in the spectral region, shown in Figure IIa-IIb, is approximately $10^{-4} \mathrm{~cm}^{-1}$ [10]. Therefore, the fraction of the total PAS signal caused by the absorption of the water is large at the low sample concentrations. The praseodymium and americium spectra were corrected for background absorption of the $0.01 \mathrm{M} \mathrm{HClO}_{4}$ solution. We did not measure any difference in the photoacoustic spectra of pure water compared to this acid concentration over the $460-515 \mathrm{~nm}$ range. The solution background spectrum was recorded on the computer and subtracted from the individual spectra. The same sample cuvette was used for all spectra.

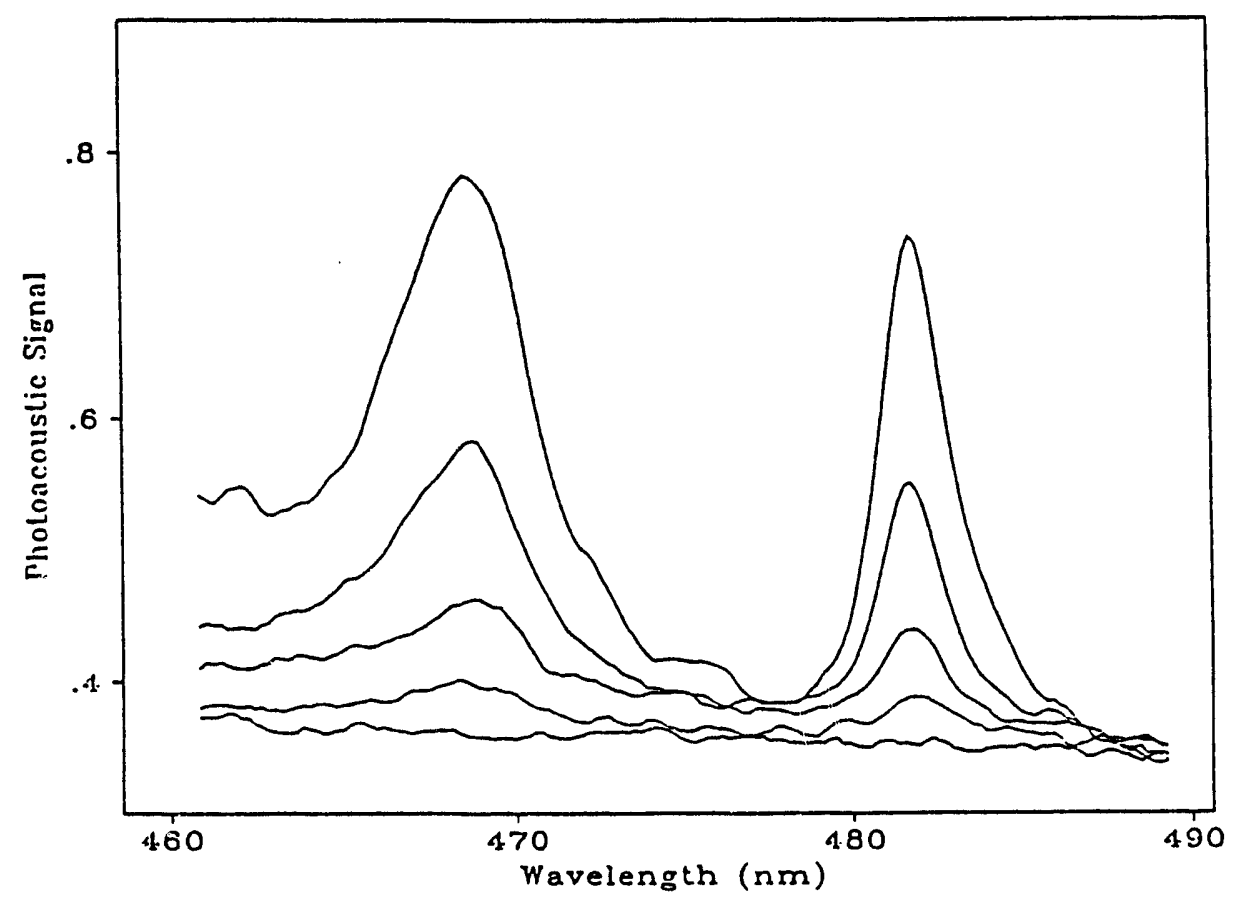

Figure Пla. Photoacoustic spectra of $\mathrm{HClO}_{4}$ and $\mathrm{Pr}^{3+}$ solutions $\left(8^{*} 10^{-6} ; 2^{*} 10^{-5} ; 5^{*} 10^{-5}\right.$; $10^{-4} \mathrm{M}$ ) with $1 \mathrm{~mJ} /$ pulse at the sample cuvette. 


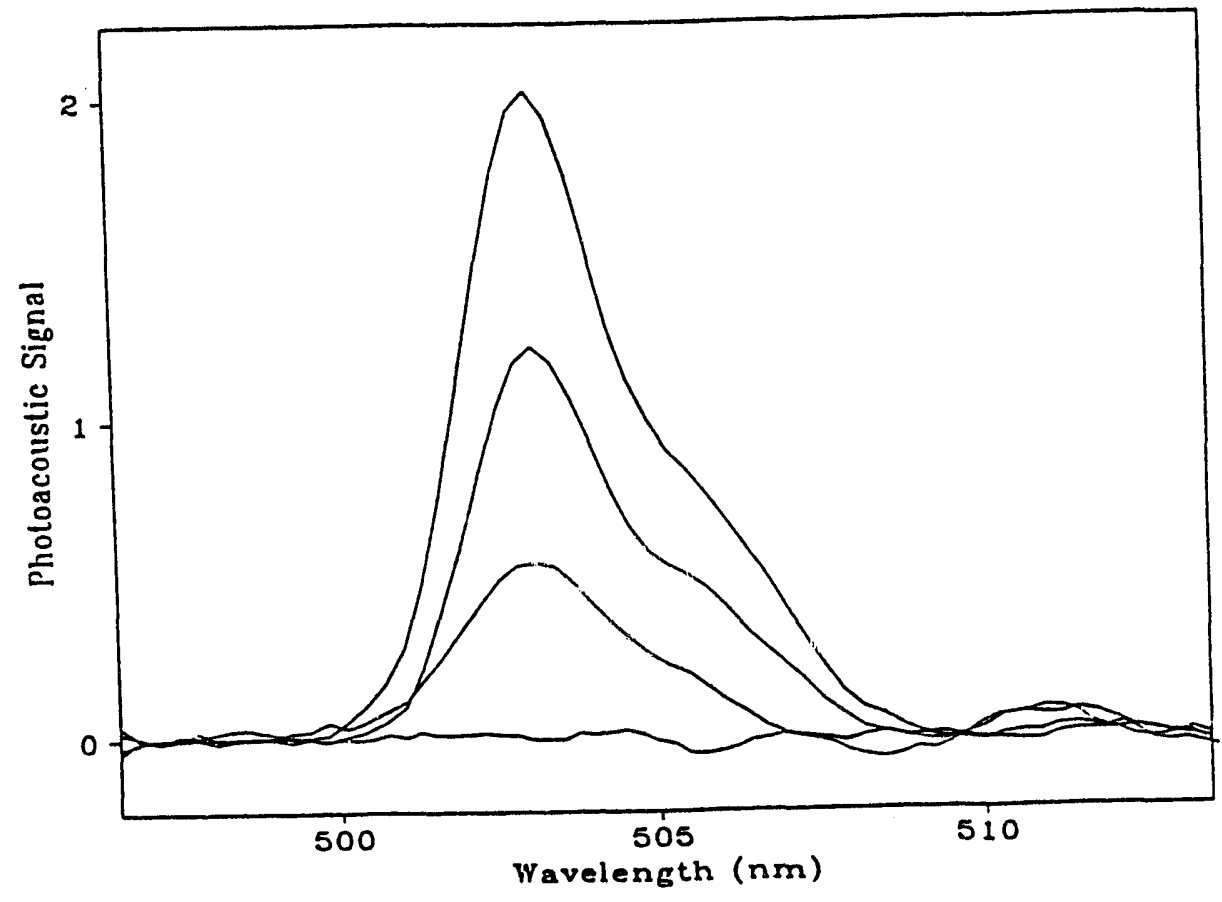

Figure IIb. Smoothed and baseline subtracted photoacoustic spectra of $\mathrm{HClO}_{4}$ and $\mathrm{Am}^{3+}$ solutions $\left(3^{*} 10^{-8} ; 6.5^{*} 10^{-8} ; 10^{-7} \mathrm{M}\right)$ with $1 \mathrm{~mJ} /$ pulse at the sample cuvette.

Beer's law linearity was observed over the range of $\mathrm{Pr}^{3+}$ and $\mathrm{Am}^{3+}$ concentrations measured (Figure III). The amplitude of the signal for the $3^{*} 10^{-8} \mathrm{M}$ solution was exactly that normally achieved in the laboratory without the fiber. The americium aquo ion has a molar absorptivity of $3801 \mathrm{~mole}^{-1} \mathrm{~cm}^{-1}$ at the $503 \mathrm{~nm}$ absorption peak. Therefore, the sensitivity limit (for signal:noise $=1$ ) would be approximately $1.4^{*} 10^{-6} \mathrm{~cm}^{-1}$. This sensitivity is comparable to that obtained by others using photoacoustic $[5,11]$ and thermal lensing spectroscopy [12-14]. Raman light generated in the fiber did not influence the absorption spectrum or the sensitivity of the photoacoustic measurements. Raman light generated in the fiber would likely have its largest influence on the absorption in the lower concentration region. This effect was not apparent from the linear Beer's Law plot.

The system described here, based on a static-volume cuvette, was a proof of principle experiment. A flow-through cuvette has been incorporated into the remote photoacoustic cell assembly to study the U(IV)- $\mathrm{H}_{2} \mathrm{O}$-Carbonate system, at uranium concentrations below the detection limits of conventional absorption spectrometers.

This optical fiber system represents a prototype remote sensor for field applications in which photoacoustic measurements could be performed in a ground water environment. 


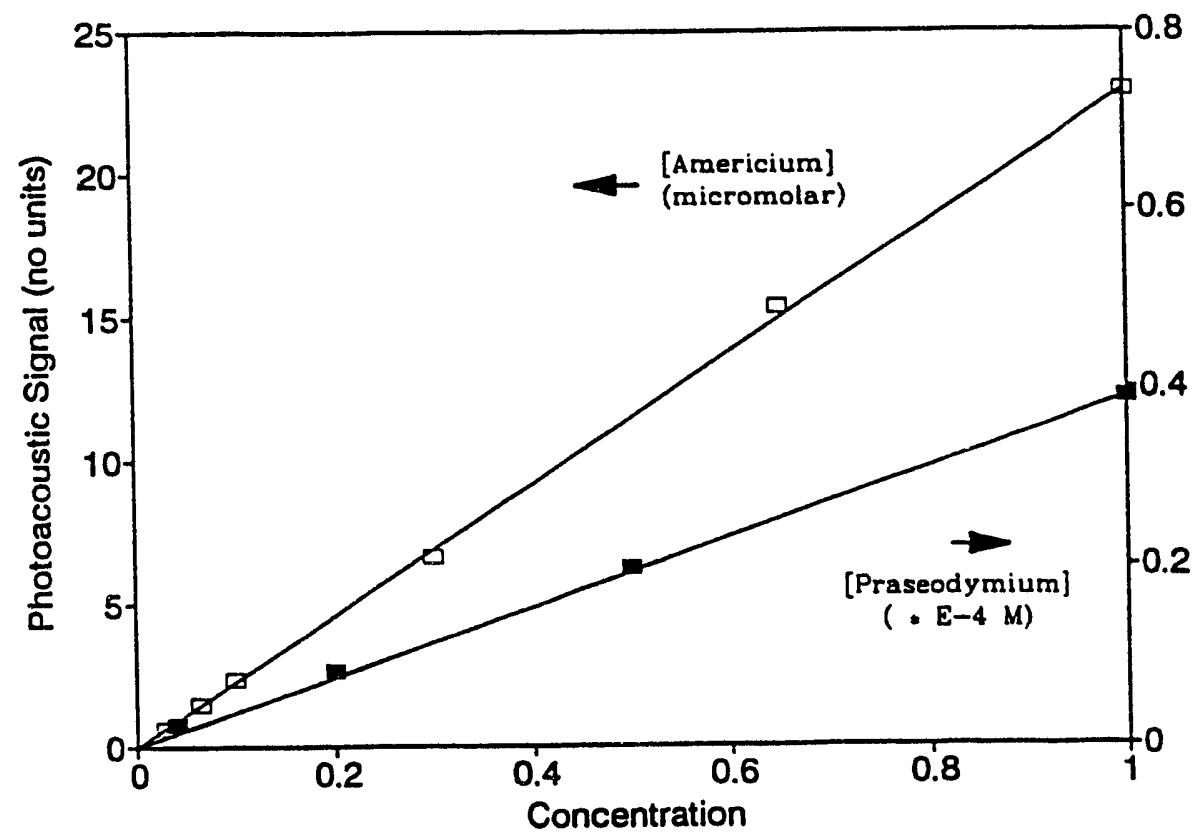

Figure III. Beer's Law plots obtained from measurements of $\mathrm{Pr}^{3+}$ and $\mathrm{Am}^{3+}$ solutions (in $0.01 \mathrm{M} \mathrm{HClO}_{4}$ media), using the remote photoacoustic spectrometer, with a $1 \mathrm{~mJ} /$ pulse at the sample cuvette.

\section{ACKNOWLEDGEMENT}

This work was supported in part by Internal Exploratory Research and Development at the Lawrence Berkeley Laboratory, and under the auspices of the U.S. Department of Energy by Lawrence Livermore National Laboratory under Contract W-7405-ENG-48. Prepared by Yucca Mountain Project (YMP) participants as part of the Civilian Radioactive Waste Management Program. The YMP project is managed by the Waste Management Project Office of the U.S. Department of Energy, Nevada Operations Office. YMP Project work is sponsored by the DOE Office of Civilian Radioactive Waste Management.

\section{REFERENCES}

1. A.C. Tam, Rev. Mod. 'hys. 58,381 (1986).

2. J.F. McClelland, Anal. Chem. 55, 89A (1983).

3. G.A. West, J.J. Barrett, D.R. Siebert and K.V. Reddy, Rev. Sci. Instrum. 54, 797 (1983).

4. C.K.N. Patel and A.C. Tam, Rev. Mod. Phys. 53, 517 (1981). 
5. R. Stumpe, J.I. Kim, W. Schrepp and H. Walter, f.ppl. Phys. B $\underline{34}, 203$ (1984).

6. W. Schrepp, R. Stumpe, J.I. Kim and H. Walther, Appl. Phys. B 32, 207 (1983).

7. J.V. Beitz, D.L. Bowers, M.M. Doxtader, V.A. Maroni, and D.T. Reed, Radiochim. Acta 44/45, 87 (1988).

8. J.V. Beitz, M.M. Doxtader, V.A. Maroni, S. Okajima, and D.T. Reed, Rev. Sci. Instrum. 61, 1395 (1990).

9. R.A. Torres, C.E.A. Palmer, P.A. Baisden, R.E. Russo and R.J. Silva, Anal. Chem. 62, 298 (1990).

10. A.C. Tam and C.K.N. Patel, Appl. Opts. 18, 3348 (1979).

11. R. Klenze and J.I. Kim, Radiochim. Acta 44/45, 77 (1988).

12. T. Berthoud, P. Decambox, B. Kirsch, P. Mauchien, and C. Moulin, Anal. Chem. 60, 1296 (1988).

13. G. Bidoglio, G. Tanet, P. Cavalli, and N. Omenetto, Inorg. Chim. Acta 140,293 (1987).

14. N. Omenetto, P. Cavalli, G. Rossi, G. Bidoglio, and G.C. Turk, J. Anal. Atom. Spectrosc. 2 , 579 (1987). 

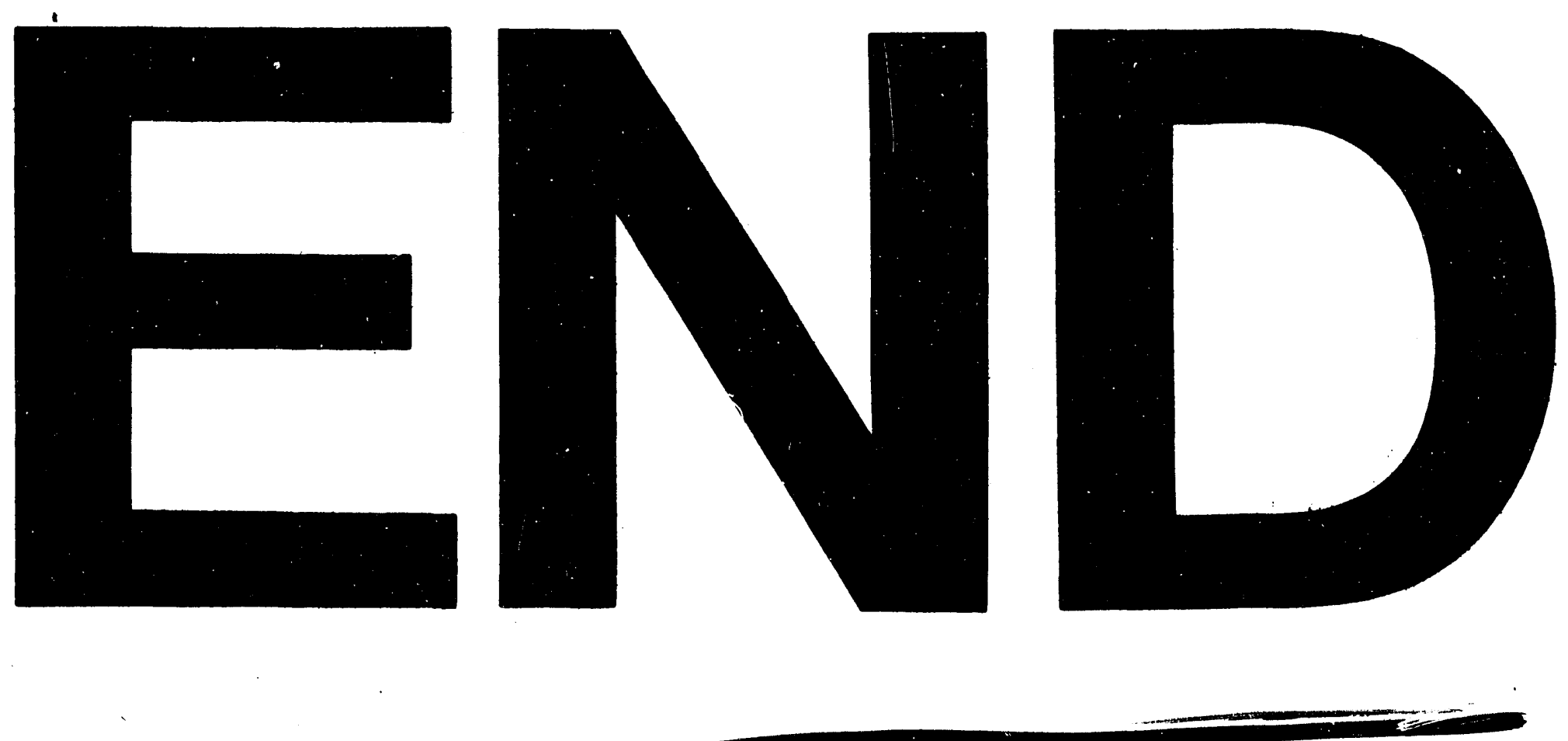

v.

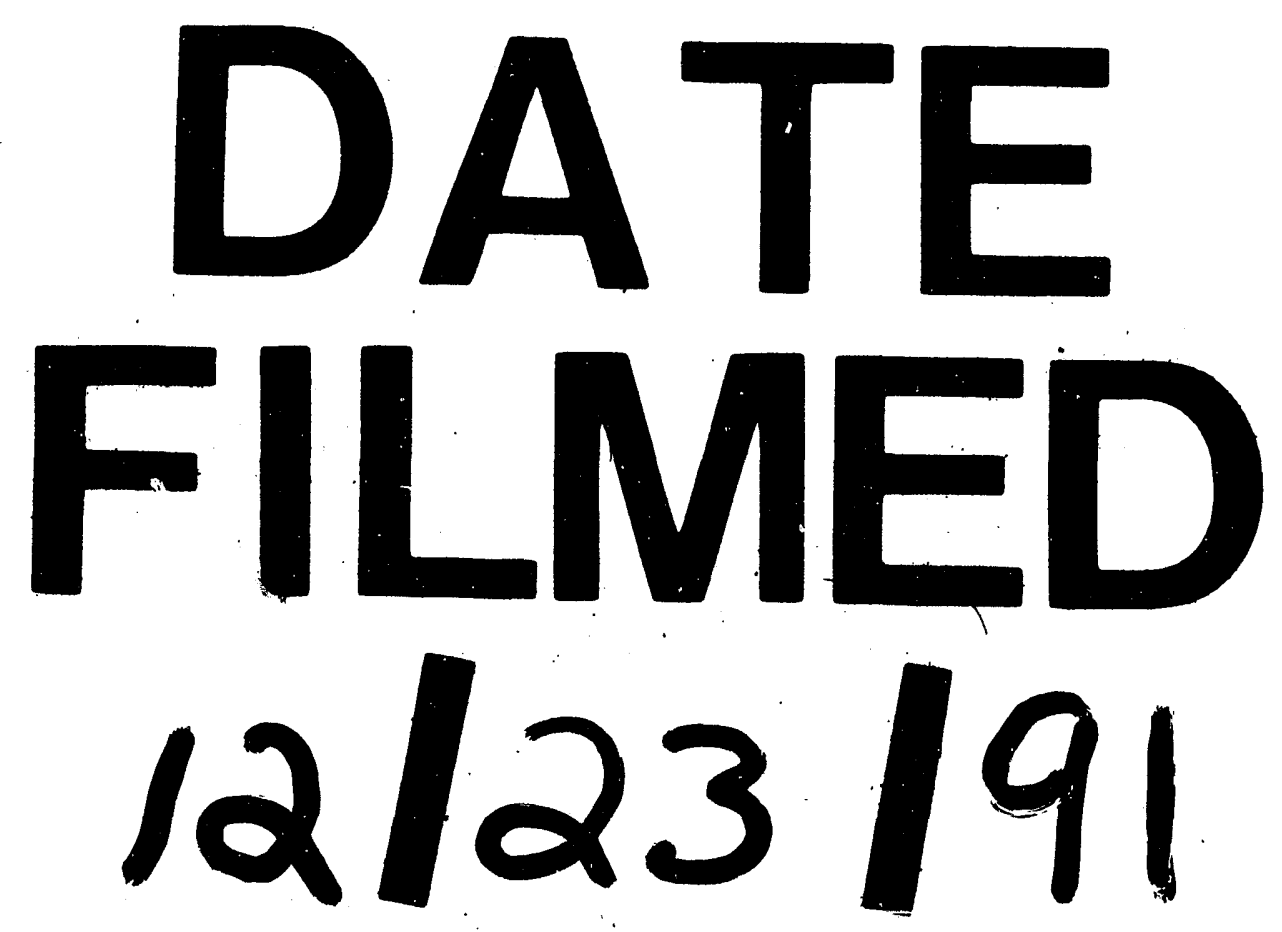

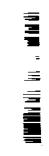


